http://jmscr.igmpublication.org/home/ ISSN (e)-2347-176x ISSN (p) 2455-0450

crossref DOI: https://dx.doi.org/10.18535/jmscr/v7i11.90

\title{
Stump Appendicitis Following Laproscopic Appendicectomy -A Case Report at PMCH
}

\author{
Authors \\ Dr Kislay Kant ${ }^{1}$, Dr H N Singh Hariaudh ${ }^{2}$, Prof. Dr Vimal Mukesh ${ }^{3}$ \\ ${ }^{1}$ JR Dept of General Surgery PMCH \\ ${ }^{2}$ Associate Professor, Dept of Surgery, NMCH \\ ${ }^{3}$ Professor, $\mathrm{PMCH}$
}

\section{Background}

Stump appendicitis is inflammation of residual appendicular Stump, a rare delayed complication of appendicectomy.

It can occur following both open and laproscopic appendicectomy.

It can create a diagnostic dilemma Delay in diagnosis and can cause serious complications.

\section{Case Report}

A 25 year old male presented with acute lower abdominal pain, vomiting and fever. He gave a history of acute appendicitis and laproscopic appendicectomy for acute appendicitis 9 years ago. Patients was not on any medication. Examination findings include scars of previous laproscopic port sites visible, abdominal tenderness in Mc Burny's point and rebound tenderness, mild localised guarding no rigidity, bowel sounds normal.

\section{Investigation}

Leucocytes counts were elevated (12300), X-ray abdomen and chest were normal. USG abdomen no cause was identifiable.
CECT abdomen and pelvis; A diffuse circumferential wall thickening involving the appendicular Stump (length $2.5 \mathrm{~cm}$ ) with presence of surrounding inflammatory fat stranding and few pan appendicial lymph nodes suggestive of Stump appendicitis.

\section{Management}

Patient general condition was better with antibiotics therapy and I. V fluids. Patient was discharged. Interval completion appendicectomy was done after 6 weeks.

\section{Procedure and Outcomes}

Under general anaesthesia standard laproscopic ports for lap appendicectomy placed. There was initial difficulty in identifying the Stump. A retrocaecal appendix with a clip applied at the end of me so appendix was identified. Mesoappendix was taken down with harmonic. Appendix was stappled at the basement. Ensuring no Stump was left behind. Patient had uneventful recovery post operatively and was discharged on day 1 . 


\section{Discussion}

Stump appendicitis was first described by Rose in 1945 following open appendicectomy .incidence of Stump appendicitis has been documented after both open and Lap appendicectomies theoretically increased incidence of Stump appendicitis in laproscopicsurgery is due to lack of 3D perspective and absent tactile feedback. Incidence of Stump appendicitis is higher following open appendicectomies $(66 \%$ of reported cases). Incidence of perforation is reported to be high following Stump appendicitis Stump appendicitis presents with similar symptomatology and signs as that of a acute appendicitis. In a patient with a history of appendicectomy further causes diagnostic dilemma.

General recommendation is to keep the Stump of appendix less than $3 \mathrm{~mm}$ to avoid risk of Stump appendicitis

\section{Conclusion}

Stump appendicitis is a rare, but serious complication of appendicectomythat mimics acute appendicitis at presentation

Diagnosis might be missed or delayed if clinician is unaware of this entity

Maticulous dissection and proper identification of appendicular based and keeping the Stump size less than $3 \mathrm{~mm}$ are prerequisites to prevent Stump appendicitis

\section{Reference}

1. Stump appendicitis a surgeon dilemma Kurt E Robert and Lee f starker et al Vol $104293 \backslash 1086808111312573336554$. 